\title{
Importanța tabloului clinic în diagnosticul sindromului Guillain-Barré
}

\author{
Tudorița-Gabriela Părângă2, Maria Obreja', Claudia-Elena Pleșca ${ }^{1,2}$, Daniela Leca',2, \\ Larisa Miftode ${ }^{1,2}$, Oana Stamateanu ${ }^{1,2}$, Elisabeta Lupu ${ }^{3}$, Egidia-Gabriela Miftode ${ }^{1,2}$ \\ ${ }^{1}$ Universitatea de Medicină și Farmacie „Gr.T. Popa“, Iași, România \\ 2Spitalul de Boli Infecțioase „Sfânta Parascheva“, Iași, România \\ ${ }^{3}$ Institutul Regional de Oncologie, Iaşi, România
}

\begin{abstract}
REZUMAT
Sindromul Guillain-Barré este o poliradiculonevrită periferică mediată imun, care se caracterizează clinic printr-o evoluție rapidă, simetrică a slăbiciunii musculare sau a paraliziei, cu sau fară simptome senzitive. Descriem cazul unui copil, de sex masculin, în vârstă de 4 ani, care se prezintă pentru slăbiciune distală la nivelul membrelor inferioare, imposibilitatea menținerii ortostatismului, tulburări de echilibru, somnolenţă alternând cu episoade de agitaţie psihomotorie şi disfonie, cefalee, simptomatologie ce a debutat cu 12 ore anterior internării. Datele clinice și de laborator, precum și evoluția bolii au pledat pentru diagnosticul de sindrom Guillain-Barré. Sub tratamentul efectuat, evoluția a fost favorabilă.

Cazul descris subliniază importanța descrierii cu exactitate a tabloului clinic și a evoluţiei pentru stabilirea diagnosticului, în absenţa totală sau parțială a datelor paraclinice. Totodată, incidența scăzută a cazurilor descrise în literatură justifică importanța raportării acestuia.
\end{abstract}

Cuvinte cheie: sindrom Guillain-Barré, poliradiculonevrită, tablou clinic, date paraclinice

\section{INTRODUCERE}

Sindromul Guillain-Barré este o poliradiculonevrită periferică mediată imun, care se caracterizează clinic printr-o evoluție rapidă, simetrică a slăbiciunii musculare sau paraliziei, cu sau fără simptome senzitive, a cărei descriere a fost făcută pentru prima dată în anul 1916 (1). Diagnosticul bolii este unul clinic, susţinut de rezultatele LCR și studiile de conducere nervoasă. Recunoaşterea precoce a bolii şi intervenţia terapeutică promptă pot scurta perioada de boală, pot reduce severitatea și necesitatea ventilației pulmonare (2).

\section{PREZENTAREA CAZULUI}

Copil de sex masculin, în vârstă de 4 ani, se prezintă pentru slăbiciune distală la nivelul membrelor inferioare, imposibilitatea menținerii ortostatismului, tulburări de echilibru, somnolenţă alternând cu episoade de agitaţie psihomotorie şi disfonie, cefalee, care au debutat brusc, cu aproximativ 12 ore anterior internării. De menţionat în antecedentele recente un episod de otită medie acută, tratat cu Cefuroxim, 7 zile, şi un episod de viroză respiratorie $\mathrm{cu}$ fenomene laringiene.

Clinic, s-a constatat o stare generală moderat influenţată, cu stare de conştienţă păstrată, eritroză palmară și facială, uşoară congestie faringiană, buze uscate, deshidratate, catar oculo-nazal, hipotonie musculară, tulburări marcate de echilibru, imposibilitatea mersului şi menţinerii ortostatismului, voce stinsă (răguşită), murmur vezicular înăsprit bazal bilateral, zgomote cardiace ritmice, fără sufluri supraadăugate, abdomen nedureros, tranzit in- 
testinal și micțiuni fiziologice, fără semne de contractură meningeană. S-a ridicat suspiciunea de poliradiculonevrită şi s-au efectuat serologii pentru enterovirusuri, Mycoplasma pneumoniae, virusul Epstein-Barr, culturi pentru enterovirusuri din materii fecale, exsudat faringian şi coproculturi pt Campylobacter. Având în vedere o posibilă infecție de tract respirator superior / otică s-a iniţiat tratament cu ceftriaxonă, la care s-a asociat dexametazonă.

În a 3-a zi de internare, la examenul fizic se constată progresia fenomenelor neurologice cu reflexe osteotendinoase abolite, fără tulburări de sensibilitate, disfonia accentuată şi dificultate la înghiţirea alimentelor solide. Se practică puncţia lombară, care relevă absenţa reacţiei inflamatorii și hiperalbuminorahie $(0,56 \mathrm{~g} / 1$, cu valori de referinţă $0-0,35$ g/l). Se efectuează radiografie toracică, care descrie infiltrat interstițial pulmonar bilateral și RMN cerebral care evidenţiază modificări de otomastoidită acută, elemente clinice care impun remanierea antibioterapiei iniţiale cu meropenem şi vancomicină. Examenul neurologic efectuat în ziua 4 evidenţiază tulburări de deglutiţie pentru lichide şi solide, ortostaţiunea şi mersul nu sunt posibile, nu controlează capul, stă în şezut cu sprijin cu dificultate, mişcările active segmentare sunt diminuate ca forţă şi viteză la nivelul membrelor superioare şi absente la nivelul membrelor inferioare, hipotonie musculară predominant la nivelul membrelor inferioare, reflexele stiloradial şi tricipital prezente, reflexul rotulian este absent bilateral, RCA prezente simetrice, RCP flexie bilateral, reflex cremasterian absent bilateral, coordonarea absentă la nivelul membrelor inferioare, la membrele superioare copilul nu colaborează, aparent fără tulburări de sensibilitate, de limbaj sau psihice. Se menţine suspiciunea iniţială de diagnostic şi se iniţiază terapia cu Imunoglobuline umane iv 5 grame pe zi, perfuzii de rehidratare, vitamine de grup B şi claritromicină po (vizând germenii atipici). Reevaluarea neurologică efectuată la 10 ore relevă disfagie pentru lichide şi solide (se practică aspirarea secreţiilor traheo-bronşice şi se recomandă inserarea sondei nazogastrice pt alimentaţie), disartrie cu voce nazonată şi hipotonia muşchilor cefei, durere la compresiunea maselor musculare, tranzit intestinal încetinit, tendinţa de retracţie a tendonului ahilian bilateral. În următoarele zile, starea generală a copilului se menţine gra- vă, cu episoade de subfebrilitate, fenomenele neurologice ascensionează la nivelul membrelor superioare, mişcările active ale acestora fiind limitate, necoordonate şi însoţite de parestezii.

Din motive obiective, nu s-a putut iniţia plasmafereza şi s-a continuat tratamentul cu imunoglobulină doză crescută la 6,5 grame.

Evoluţia ulterioară a fost relativ favorabilă, cu remisiunea lentă a fenomenelor neurologice. Recuperarea neurologică continuă treptat, iar în a 18-a zi de spitalizare se constată ameliorarea forţei musculare (menține capacitatea de prehensiune pentru câteva secunde), la ridicarea asistată în şezut menţine capul, mobilizează membrele inferioare din articulaţia şoldului şi are tentative de ridicare a acestora pe planul patului. La externare (ziua 20), copilul stă singur în şezut la marginea patului, timp de 1-2 minute, bate din palme și cântă.

Particularitatea cazului rezidă din deteriorarea neurologică foarte rapidă cu sindrom ascendent Landry, dar cu recuperarea completă la evaluarea de la o lună după externare.

\section{DISCUȚII}

După mai bine de un secol de la primul caz descris, diagnosticul și managementul unui caz de SGB rămân o provocare în practica clinică curentă. Incidența anuală a acestei patologii este de 1,5 cazuri/100.000, susceptibilitatea la bărbați este mai mare decât la femei, iar incidenta crește odată cu vârsta (3). Odată cu eradicarea poliomielitei, GBS rămâne cea mai frecventă cauză a paraliziei motorii acute la copii. Sindromul afectează mai frecvent copiii cu vârsta cuprinsă între 1 şi 5 ani, predominant de sex masculin (4). În timp ce unele studii declară o incidenţă la copii între 0,34 şi 1,34/100.000 (5), un studiu recent din 2019 susţine că sub vârsta de 2 ani cazurile apar rar, iar la copii incidenţa este de $0,6 / 100.000$ (3).

În ceea ce priveşte etiologia, studiile au demonstrat că o proporţie de aproximativ $70 \%$ dintre cazuri au fost precedate cu 1-3 săptămâni înainte de debutul simptomatologiei de episoade infecţioase acute, cel mai frecvent virale, care sunt de obicei respiratorii sau gastro-intestinale. (6).

Există o serie întreagă de agenţi infecţioşi care au fost citaţi în literatură ca factori trigger pentru GBS. Printre aceștia se numără citomegalovirusul, 
Campylobacter jejuni, virusul Epstein-Barr, virusul rujeolic, virusul gripal A, enterovirusul D68, Мyсoplasma pneumoniae și virusul Zikka (3). Infecția cu Campylobacter jejuni, a fost raportată mai frecvent în ţările asiatice și s-a asociat într-o proporție de $25-50 \%$ cu cazurile de GBS la adulţi.

Într-un alt studiu citat în literatură, Nasiri J şi colab. enumeră printre agenții infecțioși corelaţi cu debutul GBS şi virusul HIV alături de cei enumerate mai sus. Au mai fost citate în literatură cazuri de GBS postvaccinare împotriva gripei, poliomielitei, rabiei, meningitei (8), dar într-un procent mai mic decât cele care apar în contextul bolilor respective.

În cazul prezentat s-a considerat ca factor trigger posibil infecţia în antecedente virusul Epstein-Barr, enterovirusuri sau M. pneumoniae, pentru care s-au recoltat probe biologice. Anamnestic s-a exclus o infecție digestivă în antecedentele recente. Anticorpii de tip IgM pentru Mycoplasma pneumoniae au fost prezenţi într-un titru de peste $95 \mathrm{UI} / \mathrm{ml}$ (pozitiv peste $22 \mathrm{UI} / \mathrm{ml}$ ), pledând pt o infecție recentă. Serologia IgM şi Ig G pt enterovirusuri a fost negativă.

Diagnosticul de sindrom Guillain-Barré se stabilește pe criterii anamnestice, clinice şi paraclinice.

$\mathrm{Cu}$ ocazia posibilei asocieri a GBS cu o campanie de vaccinare împotriva gripei porcine în America din anii 2009/2010 Brighton Collaboration a dezvoltat un set de criterii diagnostice, care stabilesc gradul de certitudine diagnostică bazată pe semne găsite la examinarea clinică şi testele adiţionale, plecând de la nivelul 1 de diagnostic cu cel mai mare grad de certitudine și ajungând la nivelul 4 ce însumează cazuri raportate ca fiind SGB, dar cu absenţa datelor complete necesare unei clasificări ulterioare (tabelul 1) (9).

În cazul descris, avem anamneză pozitivă pentru o infecţie respiratorie în antecedente. Din punct de vedere clinic, tabloul descris este în concordanța cu criteriile Brighton (tabelul 1). Dintre criteriile menționate, următoarele au fost identificate la cazul nostru: paralizie musculară flască a membrelor, reflexe osteo-tendinoase abolite la nivelul membrelor afectate, pacientul a avut o evoluție monofazică favorabilă, deşi inițial mai lentă, iar perioada de la debutul bolii şi până la externare a fost de 21 de zile. De asemenea, din punct de vedere paraclinic, pacientul a prezentat disociaţie cito-albuminologică (absenţa reacţiei inflamatorii în LCR cu o valoa- re crescută a albuminorahiei), aspect care coincide cu unul dintre criteriile Brighton. Există mai multe studii care menţionează că disocierea citoalbuminologică în LCR este adesea absentă în stadiile precoce ale bolii. Uncini şi colab. afirmă că în primele zile de boală proteinele din LCR pot fi normale la $50 \%$ dintre cazuri (10).

TABELUL 1. Diagnosticul sindromului Guillain-Barré şi validarea criteriilor Brighton

\begin{tabular}{|c|c|c|c|c|}
\hline \multirow[t]{2}{*}{ Criterii de diagnostic } & \multicolumn{4}{|c|}{$\begin{array}{l}\text { Nivelul de certitudine } \\
\text { diagnostică }\end{array}$} \\
\hline & 1 & 2 & 3 & 4 \\
\hline Slăbiciune musculară flască bilaterală & + & + & + & $+/-$ \\
\hline $\begin{array}{l}\text { ROT abolite sau absente la membrele } \\
\text { afectate }\end{array}$ & + & + & + & $+/-$ \\
\hline $\begin{array}{l}\text { Evoluție monofazică şi durată a bolii } \\
\text { între } 12 \text { şi } 28 \text { de zile de la debut }\end{array}$ & + & + & + & $+/-$ \\
\hline Celularitate LCR 50/ $\mu \mathrm{l}$ & + & $+\underline{a}$ & - & $+/-$ \\
\hline $\begin{array}{l}\text { Concentrația de proteine în } \\
\text { LCR > valoarea normală }\end{array}$ & + & $+/-\underline{a}$ & - & $+/-$ \\
\hline $\begin{array}{l}\text { Teste de conducere nervoasă } \\
\text { înalt sugestive pentru unul dintre } \\
\text { subtipurile GBS }\end{array}$ & + & $+/-$ & - & $+/-$ \\
\hline $\begin{array}{l}\text { Absența diagnosticului diferențial pt. } \\
\text { slăbiciunea musculară }\end{array}$ & + & + & + & + \\
\hline
\end{tabular}

+ prezent,- absent, +/- prezent sau absent;

GBS = Sindrom Guillain-Barré;

a Dacă testele de conducere nervoasă nu sunt efectuate sau rezultatele nu sunt disponibile, rezultatele testelor de electrofiziologie a nervilor trebuie să fie înalt sugestive pentru GBS.

$\mathrm{Cu}$ toate acestea, cazul nostru a prezentat această disociere în proba recoltată în cea de-a treia zi de boală. Conducerea nervoasă şi studiile de electromiografie nu au fost efectuate.

Confom criteriilor Brighton, cazul prezentat se înscrie cu un grad de 2 în scorul de certitudine.

Christiaan Fokke şi colab. concluzionează într-un studiu realizat că pacienții încadraţi la diferite niveluri de certitudine diagnostică conform criteriilor Brighton nu diferă din punct de vedere al severitătiii clinice sau a evoluţiei. Există studii din literatură realizate pe loturi de pacienți încadrați preponderent la nivelurile 3 şi 4 de certitudine diagnostică conform acestor criterii, deoarece în anumite servicii investigațiile necesare nu se lucrează sau rezultatele nu au fost disponibile, fapt ce evidențiază că documentarea clară și minuțioasă a semnelor clinice ar trebui să permită o mai bună clasificare a GBS pentru ca diagnosticarea să fie posibilă atât în ţările dezvoltate, cât și în cele în curs de dezvoltare (9).

Tot în acest studiu se menţionează că în ţări precum Olanda studiile de electrofiziologie a nervului 
și analiza LCR nu se practică atunci când suspiciunea clinică de SGB este înalt sugestivă și nu există criterii clinice pentru o altă boală, fapt care întărește importanța examenului clinic la astfel de pacienți.

Diferite studii susţin că electrofiziologia nervului poate avea relevanţă prognostică, dar nu există în prezent criterii bine definite și aprobate de diagnostic electrofiziologic al sindromului GB, toate criteriile curente descrise axându-se pe diferenţierea dintre subtipuri, a cărei valoare este incertă în practica clinică curentă (9).

Imunoglobulinele intravenoase sau plasmafereza sub strictă supraveghere medicală sunt considerate tratament de elecţie de multe studii. Ambele tratamente sunt considerate eficiente în egală măsură, dar există autori care susţin că ivIG este mai ieftină datorită unei durate de spitalizare mai reduse a pacientului (13). Se recomandă ivIG în doză de $400 \mathrm{mg} / \mathrm{kg} / \mathrm{zi}$ timp de 5 zile.

În ceea ce priveşte tratamentul cazului descris, s-a optat pentru inițierea terapiei cu imunoglobulină iv, care s-a administrat începând din a 5-a zi de internare a copilului. Plasmafereza nu a fost posibilă, aşa că s-a crescut doza de imunoglobulină.

Motivul pentru care în cazul nostru s-a considerat oportună creşterea dozei de imunoglobulină ca alternativă la absența plasmaferezei este susţinut de datele din literatură $(11,12)$, care raportează corelarea unei evoluţii mai lente şi a unui prognostic mai puţin favorabil cu acele cazuri în care concentraţia de imunoglobină în ser nu atinge valorile scontate

\section{$\overline{\text { BIBLIOGRAFIE }}$}

1. Jin J, Hu F, Qin X, Liu X, Li M, Dang Y, Dang J. Very early neurophysiological study in Guillain-Barré syndrome. Eur Neurol 2018; 80(1-2):100-105.

2. Roodbol J, de Wit MY, van den Berg B, Kahlmann V, Drenthen J, Catsman-Berrevoets CE, Jacobs BC. Diagnosis of Guillain-Barré syndrome in children and validation of the Brighton criteria. $J$ Neurol 2017; 264(5):856-861

3. Wachira VK, Peixoto HM, de Oliveira MRF. Systematic review of factors associated with the development of Guillain-Barre syndrome 2007-2017: What has changed? Trop Med Int Health 2019; 24(2):132-142.

4. Sejvar JJ, Baughman AL, Wise M, Morgan OW. Population incidence of Guillain-Barré syndrome: A systematic review and meta-analysis. Neuroepidemiology 2011; 36(2):123-133.

5. Sadek AA, Abou-Taleb A, Ali WA. Outcome of Guillain-Barré syndrome in children: A prospective cohort study in a tertiary hospital in Upper Egypt. Electron Physician 2016; 8(12):3318-3324.

6. Kumar M, Aroor S, Mundkur S, Kumar S. Guillain-barré syndrome: A clinical study of twenty children. J Clin Diagn Res 2015; 9(1):SC09-12.

7. Nasiri J, Ghazavi M, Yaghini O, Chaldavi M. Clinical features and outcome of Guillain-Barré syndrome in children. Iran J Child Neurol 2018; 12(2):49-57. (fără a exista o motivaţie clară) (11). În plus, există date din literatură care susţin că ivIG este preferata la copiii mici atunci când plasmafereza este dificilă din punct de vedere tehnic (14).

Evoluția a fost lent favorabilă. Studii comparative efectuate pe adulți și copii diagnosticați cu SGB relevă un răspuns terapeutic mai bun în cazul copiilor (6). Pacientul nu a necesitat măsuri de terapie intensivă.

Deși progresele în domeniu sunt evidente, SGB are o rată a mortalităţii în Europa şi America de Nord, care variază între 3 şi 7\%, chiar și în cazul utilizării plasmaferezei şi imunoglobulinelor, cele mai bune terapii existente în prezent (10).

\section{CONCLUZII}

Cazul descris subliniază importanța descrierii cu exactitate a tabloului clinic și a evoluţiei pentru stabilirea diagnosticului, în absenţa totală sau parțială a datelor paraclinice. Datele din literatură referitoare la incidenţa scăzută a acestei patologii, mai ales la copii, faptul că diagnosticul se stabilește clinic, fară biomarkeri, pe criterii nu foarte clar definite și unanim acceptate la o boală cu un tablou clinic heterogen, justifică interesul clinicienilor şi, implicit, şi al nostru de a investiga și publica aceste cazuri cu scopul de a atrage atenţia tinerilor medici asupra necesității inițierii rapide a algoritmului de diagnostic şi a terapiei adecvate chiar în absenţa unor explorări paraclinice.

Conflict of interest: none declared Financial support: none declared

8. Wajih Ullah M, Qaseem A, Amray A. Post vaccination Guillain-Barré syndrome: A case report. Cureus 2018; 10(4):e2511.

9. Fokke C, van den Berg B, Drenthen J, Walgaard C, van Doorn PA, Jacobs BC. Diagnosis of Guillain-Barré syndrome and validation of Brighton criteria. Brain 2014; 137(1):33-43.

10. Uncini A. Guillain-Barré syndrome: What have we learnt during one century? A personal historical perspective. Rev Neurol (Paris) 2016; 172(10):632-644.

11. Van Doorn PA, Kuitwaard K, Walgaard C, van Koningsveld R, Ruts $L$, Jacobs BC. IVIG treatment and prognosis in Guillain-Barré syndrome. J Clin Immunol 2010; 30(S1):74-78.

12. Kuitwaard K, de Gelder J, Tio-Gillen AP, Hop WC, van Gelder T, van Toorenenbergen AW, van Doorn PA, Jacobs BC. Pharmacokinetics of intravenous immunoglobulin and outcome in Guillain-Barré syndrome. Ann Neurol 2009; 66(5):597-603.

13. McGrogan A, Madle GC, Seaman HE, de Vries CS. The epidemiology of Guillain-Barré syndrome worldwide. A systematic literature review. Neuroepidemiology 2009; 32(2):150-163.

14. Jasti AK, Selmi C, Sarmiento-Monroy JC, Vega DA, Anaya JM, Gershwin ME. Guillain-Barré syndrome: Causes, immunopathogenic mechanisms and treatment. Expert Rev Clin Immunol 2016; 12(11):1175-1189. 